\title{
SCIDiC
}

International Journal of Dentistry and Oral Science (IJDOS)

ISSN: 2377-8075

\section{Medicinal Value and Oral health Aspects of Acacia Catechu - An Update}

Research Article

Lakshmi. T

Associate Professor, Department of Pharmacology, Saveetha Dental College, Saveetha Institute of Medical and Technical Sciences ,Saveetha University, Chennai, India.

\section{Abstract}

Acacia catechu Willd (Fabaceae), commonly known as catechu and black cutch is an important medicinal plant, especially in Asia. Several phytochemical compounds have been isolated and characterized from $A$. catechu which include 4-hydroxybenzoic acid, kaempferol, quercetin, 3, 4, 7-trihydroxyl-3,5-dimethoxyflavone, catechin, rutin, isorhamnetin, epicatechin, afzelechin, epiafzelechin, mesquitol, ophioglonin, aromadendrin, and phenol and the presence of these active compounds have been implicated for its myriad biological effects. This review focus on the actions of A. catechu for its medicinal value.

Keywords: Acacia catechu; Phytochemical; Biological; Medicinal; Active Compounds.

\section{Introduction}

Diseases that are system oriented or infectious disorders challenge human health, With the advanced diagnostic and imaging techniques, identification of diseases (minor and major) has become easier. Appropriate precaution and treatment facilitate the long living of human beings with good quality of life. To treat the systemic illness, as well as the infectious diseases drug treatment is necessary. Drugs can be derived from synthetic chemicals as well as plant and animal origin [1]. The pros and cons of synthetic drugs are taken in to consideration. Synthetic drugs are created in laboratories and causes unacceptable side effects. Herbal drugs are thought to be effective because people have been using them for thousands of years and are reporting positive results. It's considered to be more pure and healthier for the body.

Holistic therapy has been shown to be effective in treating cancer, memory deficit and Alzheimer, atherosclerosis, diabetes and cardiovascular diseases [2]. They also possess anti oxidant effects which reduces the toxicity of some toxic agents .

Herbal drugs produce bioactive compounds that are used primarily for the management of infectious diseases. These bioactive compounds acts on different systems of animals including man, and act through interfering in the metabolism of microbes infecting them. The microbes may be pathogenic or symbiotic. The bioactive compounds play a promising role in regulating host-microbe interaction [3]. Hence there is a need for the identification of bioactive compound in plants, their isolation, purification and characterization of active ingredients in crude extracts by various analytical methods.

\section{Medicinal Properties Of Acacia Catechu}

The medicinal properties of plants could be based on the antioxidant, antimicrobial, antipyretic, antidiabetic, anticancer, Immunomodulatory effects of the phytochemicals in them [4]. Herbal drugs are economical when compared to the synthetic drugs. Synthetic drugs have been reported to have many adverse effects. Now the healthcare practioner concern is whether it is synthetic or herbal the vital criteria for the utilization of medicine is safety, quality, effectiveness, Identity, purity and stability [5]. Majority of Indian population have access to practice the traditional medicines to treat many diseases.

\section{Herbal Medicine Impact On Global Health}

Medicinal plants constitute an effective source of traditional (Ayurvedic, Chinese, Homeopathic and Unani) and alternative medicine [6]. India's herbal and phytomedicine industries have an annual turnover of about Rs.4000-6000 crore and attains huge export ability in the market (Patwardhan,2004).Stringent quality

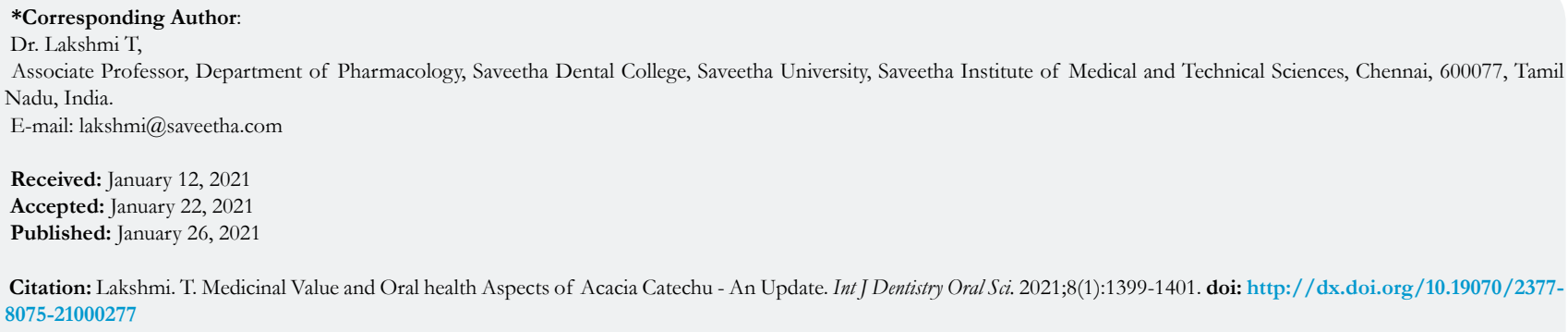

Copyright: Lakshmi. $\mathbf{T}^{\circ}$ 2021. This is an open-access article distributed under the terms of the Creative Commons Attribution License, which permits unrestricted use, distribution and reproduction in any medium, provided the original author and source are credited. 
parameters like quality control, safety, efficacy are mandatory to export herbal drugs to western countries like Canada and America [7]. China is the biggest producer as well as exporter of medicinal plants, accounting $30 \%$ of total world trade followed by korea, US and India.China with exports of over 12,000 tonnes per annum and India with 32,600 per annum dominate the international markets [8]. Japan, US, Germany France, Italy, Malaysia and Spain are major market. Hamburg is the world trading centre in medicinal plants [9].

\section{Present And Future Scenario Of Herbal Drugs}

Plant based drugs (medicinal plants) represent more than 50\% of all the drugs in clinical utility in the world [10]. During the past few decades, Several drugs have been derived from medicinal plants including Dioscorea species derived diosgenin from which all anovulatory contraceptive agents have been derived; reserpine and other antihypertensive and tranquilizing alkaloids from Rauwolfia species; pilocarpine to treat glaucoma and vinca Alkaloids (Vincristine, Vinblastin) as a potent anticancer drugs, opium ( $\mathrm{Pa}-$ paver somniferum )as an potent analgesic, atropine (Atropa belladonna) to treat Organophosphorus poisoning. There is a developing interest in the field of herbal medicine, Global demands are raised in the use of the herbal medicine, due to increasing trend towards self-medication, reduction in cost of the synthetic drugs, various international and national health care forum were improving the status of herbal medicine industry and the interest of industrial sectors in isolating useful compounds from the plants [11].

In India most of rural population use herbal medicine for treatment of various infectious diseases [12]. A key challenge in the utilisation of plant based products is to assess the toxicological, epidemiological, and other data and the verification of herbal materials used [13].

\section{Herbal Drugs - Quality Aspects}

Quality control is mandatory for the global standardisation and herbal drug trading. WHO and AYUSH (Ayurveda, Yoga, Unani, Siddha, Homeopathy) has recognised the need to ensure quality control of natural products with the application of suitable standards. Indian Pharmacopoeia, British Pharmacopoeia, Japanese Pharmacopoeia and United State Pharmacopoeia includes the monograph and quality control test for various herbal drugs used in their countries [15].

\section{Medicinal Plants and Clinical Uses}

The medicinal plants are widely used by the traditional medical practitioners for curing various diseases in their day-to-day practice. Ginseng (Panax ginseng) is an adaptogen, anti stress, immunity enhancer, tonic, anti diabetic. turmeric (Curcuma longa) is an anti-inflammatory, anti- arthritic, anti-cancer, antiseptic agent, milk thistle (Silybum marianum) possess anti oxidant, liver tonic activity. ginkgo (Ginkgo biloba) is a Adaptogenic, Anti ageing, Anti depressant, alzheimer, cardio tonic agent. St. John's Wort (Hypericum perforatum) acta as an anti depressant, In sleep disorder, Liquorice (Glycyrrhiza glabra) possess Antiviral, Antiinflammatory, Antioxidant and Hepatoprotective properties Anti-ulcer. [16].

\section{Acacia Catechu As A Promising Medicinal Plant}

The botanical name of khadira is Acacia catechu. In Tamil it is known as Karungali.The Sanskrit word Khadira literally means that which alleviates the diseases and stabilizes the body [17]. It is a medium sized thorny deciduous tree grows up to 13 meters in height. Leaves are bipinnately compound, leaflets paired, main rachis pubescent, with large conspicuous gland near the middle of the rachis. Flowers are pale yellow, sessile, found in axillary spikes. Fruits show flat brown pods, with triangular beak at the apex, shiny, narrowed at base. Seeds 3-10 per pod. The gummy extract of the wood is called katha or cutch [18].

A. catechu occurs naturally in mixed deciduous forests and savannas of lower mountains and hills. It is especially common in the drier regions on sandy soils of river banks and water sheds. It is native in India, Myanmar, Nepal, Pakistan, Thailand, Exotic in Indonesia, Kenya, Mozambique. Parts used are Bark, Leaves, Heartwood, Seed.

Acacia catechu (Family: Fabaceae and subfamily: Mimosoideae.) is widely used in Ayurveda for many diseases and mainly for skin diseases. Most of the people in Kerala use karungali water for drinking purpose. There are a number of ayurvedic formulations, which contain Khadira as one of the active ingredients. Acacia catechu is highly valuable for its powerful astringent and antioxidant activities. It is commonly known as Katha, which is an indispensable ingredient of pan that is beetle leaf preparation chewed in India. It is useful in dental, oral and throat infections, and as an astringent for reducing oozing from chronic ulcers and wounds. $[19,20]$.

\section{Therapeutic Aspects Of Acacia Catechu}

The concentrated aqueous extract known as Khair gum or cutch is an astringent, cooling and digestive, beneficial in cough and diarrhea, applied externally to ulcer, boils and skin eruptions .It is used in the treatment of passive diarrhea either alone or in combination with cinnamon or opium [21, 22]. The bark of Acacia catechu in combination with other drugs is prescribed for snake bite The seeds of the plant are reported to possess hypoglycemic activity when tested in vivo. Acacia catechu also shows hypotensive effect The decoction of bark mixed with milk is taken to cure cold and cough (Gunindro et al, 2013). Acacia catechu is useful as a topical agent for sore gums and mouth ulcers. This agent has been commonly used in India as an ointment for indolent ulcers. Other uses include arresting nose bleeds and acting as a contraceptive. Chronic gonorrhea can be treated with an infusion of catechu $[23,24]$.

\section{Phytochemical Constituents Of Acacia Catechu}

Acacia catechu exhibits various pharmacological effects like antipyretic, anti-inflammatory, antidiarrhoeal, hypoglycaemic, hepatoprotective, antioxidant and antimicrobial activities .Main chemical constituents of Acacia catechu leaves are catechin, (-) epicatechin,epigallocatechin, epicatechin gallate, Epigallocatechin galleterocatechin,phloroglucin,protocatechuic acid, quercetin, ellagic acid, porifera sterol glucosides, porifera sterolacy glucosides, lupenone, lupeol, kaempferol, dihydrokaemferol, taxifolin, (+)- 
afzelchin gum and mineral. The chief phytoconstituent of the heartwood are catechin and epicatechin. Catechins have siginificant antioxidant and antimicrobial effects $[25,26]$.

\section{Acacia Catechu as an Hepatoprotective Agent}

Acacia Catechu heartwood extract possesses significant hepatoprotective activity. Cyanidanol, an active principle of Acacia catechu, is claimed to be effective in treating liver diseases .ethylacetate extract of heartwood of Acacia catechu decreased carbontetrachloride -induced elevated enzyme levels in acute and chronic models of liver damage. The results indicated some form of repair of the structural integrity of the hepatocyte cell membrane or regeneration of damaged liver cells. Biochemical and histopathological parameters substantiated the efficacy of the extract. The hepatoprotective activity of Acacia catechu could be due to the presence of bioflavonoids which have hepatoprotective and antioxidant properties [27].

The hepatoprotective activity was investigated in Acacia catechu heartwood extract on CCl4 (Carbon tetra Chloride) induced liver damage in rats. Blood and tissue biochemical assays have been studied for evaluation of hepatoprotection. From the results of the parameters done it is clear that Acacia catechu gave best recovery for hepato protection [28].

\section{Acacia Catechu On Oral Health}

Oral microbial flora is dominated by gram positive microorganisms, hence dental plaque which is formed on the tooth surface contains gram positive cocci and bacteria. The use of natural products has been one of the most successful strategies for the discovery of new drugs. Various botanicals have been reported to inhibit the growth of several oral microrganisms particularly Streptococcus mutans and thus prevent caries. Acacia catechu is widely used as a traditional medicine for treatment of various diseases [29] Several literature study proves its efficacy as antibacterial, antioxidant, anti inflammatory, wound healing activity. On the other context this herb is valuable in treatment of dental infections. the antibacterial compound Epi-catechin present in Acacia catechu may be responsible for anti caries and antiplaque activity [30].

\section{Conclusion}

Acacia catechu is used in traditional medicinal system for various diseases. Various parts of the tree viz., bark, leaves and heartwood possess diverse pharmacological actions. many studies have been carried out to evaluate its anti-bacterial, anti-oxidant, anti- diabetic activity of the extract. This review enlightens the therapeutic aspects of Acacia catechu and its applications.

\section{References}

[1]. Haq I. Safety of medicinal plants. Pak J Med Res. 2004; 43(4): 203-10.

[2]. Karimi A, Majlesi M, Rafieian-Kopaei M. Herbal versus synthetic drugs; beliefs and facts. J Nephropharmacol. 2015 Jan 1; 4(1): 27-30. PMID: 28197471.

[3]. Adesokan AA, Yakubu MT, Owoyele BV, Akanji MA, Soladoye AO, Lawal OK. Effect of administration of aqueous and ethanolic extracts of Enantia chlorantha stem bark on brewer's yeast-induced pyresis in rats. African Journal of Biochemistry Research. 2008; 2(7): 165-9.
[4]. Cowan MM. Plant products as antimicrobial agents. Clin Microbiol Rev. 1999 Oct; 12(4): 564-82. PMID: 10515903.

[5]. Chopra A, Doiphode VV. Ayurvedic medicine. Core concept, therapeutic principles, and current relevance. Med Clin North Am. 2002 Jan; 86(1): 75-89. PMID: 11795092.

[6]. Waxler-Morrison NE. Plural medicine in Sri Lanka: do Ayurvedic and Western medical practices differ? Soc Sci Med. 1988; 27(5): 531-44. PMID: 2976194.

[7]. Patwardhan B, Vaidya AD, Chorghade M. Ayurveda and natural products drug discovery. Current science. 2004 Mar 25: 789-99.

[8]. Gupta AK. Quality standards of Indian medicinal plants. Volume 1. Quality standards of Indian medicinal plants. Volume 1. 2003.

[9]. Kala CP. Medicinal Plants in Active Trade at Haridwar City of Uttarakhand State in India. Medicinal and Aromatic Plants. 2015; 4: 204.

[10]. Sharma S. Current status of herbal product: Regulatory overview. J Pharm Bioallied Sci. 2015 Oct-Dec; 7(4): 293-6. PMID: 26681886.

[11]. Vaidya AD, Devasagayam TP. Current status of herbal drugs in India: an overview. J Clin Biochem Nutr. 2007 Jul; 41(1): 1-11. PMID: 18392106.

[12]. Mukherjee PK, Wahile A. Integrated approaches towards drug development from Ayurveda and other Indian system of medicines. J Ethnopharmacol. 2006 Jan 3; 103(1): 25-35. PMID: 16271286

[13]. Sahoo N, Manchikanti P, Dey S. Herbal drugs: standards and regulation. Fitoterapia. 2010 Sep; 81(6): 462-71. PMID: 20156530

[14]. Calixto JB. Efficacy, safety, quality control, marketing and regulatory guidelines for herbal medicines (phytotherapeutic agents). Braz J Med Biol Res. 2000 Feb; 33(2): 179-89. PMID: 10657057.

[15]. Petrovska BB. Historical review of medicinal plants' usage. Pharmacogn Rev 2012 Jan;6(11):1-5. PMID: 22654398.

[16]. Kumar R, Kaur R, Singh AP, Arora S. Diminution of hepatic response to 7 , 12-dimethylbenz $(\alpha)$ anthracene by ethyl acetate fraction of Acacia catechu willd. through modulation of xenobiotic and anti-oxidative enzymes in rats. PLoS One. 2014 Feb 27; 9(2): e90083. PMID: 24587216.

[17]. Dashtdar M, Dashtdar MR, Dashtdar B, Shirazi MK, Khan SA. In-Vitro, Anti-Bacterial Activities of Aqueous Extracts of Acacia catechu (L.F.)Willd, Castanea sativa, Ephedra sinica stapf and shilajita mumiyo Against Gram Positive and Gram Negative Bacteria. J Pharmacopuncture. 2013 Jun; 16(2):15-22. PMID: 25780663.

[18]. Saha MR, Dey P, Begum S, De B, Chaudhuri TK, Sarker DD, et al. Effect of Acacia catechu (L.f.) Willd. on Oxidative Stress with Possible Implications in Alleviating Selected Cognitive Disorders. PLoS One. 2016 Mar 7; 11(3): e0150574. PMID: 26949964.

[19]. Dubey N, Dubey N, Mehta R, Saluja A. Estimation of catechin in Ayurvedic oil formulations containing Acacia catechu. J AOAC Int. 2009 JulAug;92(4):1021-6. PMID: 19714967.

[20]. Gunindro N, Devi KP, Singh TI. Effects of Acacia catechu on intestinal absorption of glucose in rats. J. Chem. Pharm. Res. 2013; 5: 78-81.

[21]. Lakshmi T, Kumar A. Preliminary phytochemical analysis \& invitro antibacterial activity of Acacia catechu willd Bark against Streptococcus mitis, Streptococcus sanguis \& Lactobacillus acidophilus. International Journal of Phytomedicine. 2011 Oct 1; 3(4): 579.

[22]. Lakshmi T, Geetha RV, Roy A. In vitro evaluation of anti bacterial activity of Acacia catechu willd. heartwood extract. Int J Pharm Biosci. 2011; 2(2): B188-92.

[23]. Lakshmi T, Rajendran R, Madhusudhanan N. Chromatographic fingerprint analysis of Acacia catechu ethanolic leaf extract by HPTLC Technique. Int. J Drug Development and Research. 2012; 4(1): 180-5.

[24]. Lakshmi T, Rajendran R. Estimation of biomarker epicatechin in ethanolic bark extract of Acacia catechu willd by HPLC method. Journal of Pharmaceutical Sciences and Research. 2012 Mar 1; 4(3): 1764.

[25]. Lakshmi.T, Rajendran.R, Antony silvester. Evaluation of heavy metal analysis in ethanolic leaf extract of Acacia catechu as an indicator of pollution by atomic absorption spectrophotometric (FAAS) analysis. Int Res J pharm. 2013; 4: 109-112.

[26]. Bimla, Meera, Chander, Jagdish, Kalidhar SB. A Review on the chemistry and bioactivity of Acacia Spp., J Med Aro Plants Sci. 2005; 27: 51-90.

[27]. Ray D, Sharatchandra KH, Thokchom IS. Antipyretic, antidiarrhoeal, hypoglycaemic and hepatoprotective activities of ethyl acetate extract of Acacia catechu Willd. in albino rats. Indian journal of pharmacology. 2006 Nov 1; 38(6): 408.

[28]. Pingale SS. Hepatoprotection by Acacia catechu in $\mathrm{CCl} 4$ induced liver dysfunction. Int J Pharm Sci Rev Res. 2010; 1: 150-4

[29]. Lakshmi T, Ezhilarasan D, Vijayaragavan R, Bhullar SK, Rajendran R. Acacia catechu ethanolic bark extract induces apoptosis in human oral squamous carcinoma cells. J Adv Pharm Technol Res. 2017 Oct-Dec; 8(4): 143-149. PMID: 29184846

[30]. Lakshmi T, Kumar A. Preliminary phytochemical analysis $\&$ invitro antibacterial activity of Acacia catechu willd Bark against Streptococcus mitis, 